\title{
Framed versus Masonry Structures Built on Flat or on Sloping Grades with or Without Upper Setbacks
}

\author{
A Comparative Discourse
}

\author{
Samir H. Helou Ph. D., P. E. \\ Civil Engineering Department \\ An-Najah National University \\ Nablus, Palestine
}

\begin{abstract}
A widely followed practice in the local vernacular reinforced concrete construction industry is to build major edifices on levelled terrains; this is because most urban areas in Palestine enjoy hilly topography. Moreover, city planning regulations mandate, quite often, setbacks at upper floor levels. Thorough seismic analysis is a requirement imposed by local governments and since Palestine lies in an active earthquake prone region, the subject of adequate scrutiny of the present construction practices demands added attention. More often than not, building facades are primary constructed of stone with lean concrete backing, so called infill walls. At times, such walls are constructed centered at the column lines of the periphery columns or they may be constructed offset outward. Towards this objective, a repertoire of bare framing patterns are investigated along with judiciously placed masonry walls. The selected structures cover a spectrum of forms frequently adopted by architects. In four of the selected forms, the structure enjoys slight yet gradual vertical irregularity; one structure forms the basis for comparison. Furthermore, horizontal geometric symmetry is intentionally maintained in all floor plans together with square section columns; this confines attention to the impact of the general structural configuration and façade infill-wall forms on the present narrative. The comparison of the different construction systems and between the various structural numerical models includes, inter alias, the standard dynamic parameters in addition to the lateral deflection and force distribution. Standard Seismic Analysis is conducted based on the Response Spectrum Method. The present study scrutinizes the adequacy of the common construction trends and offers prudent design recommendations.
\end{abstract}

Keywords - Irregular Structure; Response Spectrum Analysis; Infill Walls; Base Shear; Strut Elements.

\section{INTRODUCTION}

Building construction practice in Palestine generally calls for the construction of bare reinforced concrete frames braced by masonry infill walls, albeit at times such walls are offset outward. Moreover, land formation in Palestine is mostly comprised of rolling hills; therefore, architects are frequently compelled to adopt vertically irregular design forms dictated by the sloping topography. Moreover, municipal regulations mandate vertical setbacks at higher levels, a feature that compounds vertical irregularities; this is becoming an indispensable and a ubiquitous architectural design practice. Furthermore, designing a seismically resistant structure is an obligatory requirement according to local government bylaws because Palestine lies well within an active earthquake prone zone. Seismic resistance is imperative for avoiding unwarranted repair cost and for protecting against loss of life. The present study exercise tackles structures having the aforementioned features i.e. structural frames with infill masonry walls. The structural forms selected focus on the influence of infill walls on the respective behavior, hence columns of square sections are assigned and span lengths are equal in the main and in the transverse direction. Moreover, the investigated structures have similar floor plans with different column sections at different floor levels leading to slight gradual stiffness irregularity as stipulated in ASCE 7-16 [12.3.2.2]. Masonry infill walls are present on all facades yet they are judicially located at edge panels to reflect architects' wishes of including curtain walls. Moreover, modeling techniques follow the respective construction practice. Therefore, it is prudent to allude to modeling such walls by assigning a distributed load equal to the weight of the wall within the panel on the edge beams when they are constructed offset to the periphery column lines. When masonry walls happen at the centerlines of the periphery columns, they are modeled as compression struts following the Pauli and Priestly model. The comparative discourse includes, but is not limited, to the fundamental frequencies, story displacements and bending moment distribution along the height of the various buildings.

The present narration focuses on seismic analysis following the approximate yet standard linear elastic method, i.e. the Response Spectrum Method.

\section{BRIEF PRESENTATION OF SEISMIC ANALYSIS PROCEDURE:}

The present undertaking proceeds by the Response Spectrum Method of analysis. In this approximate method, which is popular in seismic engineering, the force distribution is based on the natural modes of vibration. Detailed information about the investigated structural is obtained from a modal extraction exercise. However, to guarantee that most of the structural mass is included in the 
analysis, which most codes set at 90\%, 12 eigenvectors are included in the present undertaking. The Response spectrum method involves the calculation of the maximum values of displacements or forces contributed by each mode. When building structures enjoy a closely spaced band of frequency values, the Complete Quadratic Combination method is used for modal combinations while the Square Root Sum of the Squares is used for directional combination. The procedure is recommended for structures that are medium or high in elevation with a vertical stiffness irregularity. However, running the Equivalent Lateral Load method in both directions remains indispensable for quantifying appropriate scaling factors.

\section{NUMERICAL STRUCTURAL MODELING:}

Five medium rise structures are investigated; they are comprised of a G+10 storeys having four bays in one direction and five bays in the orthogonal direction; a uniform grid of 5-meter spacing is selected in both directions. The Storey height at all levels is 3.0 meters. The flooring system is comprised of 15-centimeter thick slabs resting on drop beams yet defined as diaphragms. Columns and beams are modeled in ETABS using two node linear frame elements. A rigid diaphragm action is assigned to all slabs to ensure integral lateral inclusion of all beams of each floor. The response spectrum selected is a smooth one with soil profile $\mathrm{C}$ and a damping of $5 \%$. The loads and the architectural modules are in accordance with standard vernacular building predilection. Table 1 shows pertinent data. Four of the structural models are slightly irregular in the vertical direction while one model is regular and forms the basis for comparison. All structures share common topology, comprised of identical structural elements and having the type of ordinary moment resisting frames. A total fixity is assigned for all ground supports. The mass source in all models is defined as the total dead load plus $25 \%$ of the assigned live load. The models of the masonry exterior infill walls are as follows:

- $\quad$ M 1: A structure built on a plain ground with no setbacks at higher levels. This model forms the benchmark for subsequent comparison.

- $\quad$ M 2: A structure built on a sloping ground with no setbacks at higher levels.

- M 3: A structure built on plain ground yet with backside setback at higher levels.

- M 4: A structure built on a sloping ground with backside setback at higher levels.

- M 5: A structure built on a sloping ground with front setback at higher levels.

The bare frame models are marked F1 through F 5 . Masonry infill walls constitute effective elements for resisting lateral forces. Pauley and Priestly macro method for modeling infill walls with no window openings is invoked for the present exercise. For the middle strut the width is one eighth of the diagonal length and the off diagonal ones equal to one sixteenth of the diagonal length. In the following narration $70 \mathrm{~cm}$ and $35 \mathrm{~cm}$ are the selected strut widths. They are placed in both directions while all concrete struts are meant to resist compression forces only; to ensure this they are defined as compression only elements. The location of the off diagonal struts is at $\alpha$ distance from either end of the beam.

$$
\alpha(\mathrm{mm})=\frac{\pi}{2} \sqrt[4]{\frac{E_{c} I_{c} h_{m}}{E_{m} t \sin (2 \theta)}}
$$

In which,

$\mathrm{E}_{\mathrm{c}}$ is the modulus of elasticity in MPa for the column material

$\mathrm{E}_{\mathrm{m}}$ is the modulus of elasticity in MPa for the masonry material

$I_{c}$ is the moment of inertia of the column section in $\mathrm{mm}^{4}$

$\mathrm{h}_{\mathrm{m}}$ is the height of the masonry infill wall

$\mathrm{t}$ is the thickness of the masonry infill wall

$\theta$ is the angle in degrees of the inclination of the equivalent diagonal strut with the horizontal

The numerical analysis is conducted under the assumption that the construction material is homogeneous, isotropic and elastic. P-Delta analysis is deemed necessary considering the scope of analysis; each nodal point has six degrees of freedom, three translational and three rotational. The land slope selected is rather steep because it represents actual field conditions in most geographic localities in Palestine particularly in the city of Nablus. Furthermore, one set of the mentioned structural configurations is analyzed under distributed loads meant to represent the masonry walls. Those structures are labelled ML 1 through ML 5. In such a formation, the masonry walls are built offset to the column line. The following are the assigned loads and the associated dynamic analysis parameters.

- $\quad$ The live load is $3 \mathrm{KN} / \mathrm{m}^{2}$

- The superimposed dead load is $3 \mathrm{KN} / \mathrm{m}^{2}$

- The distributed load to represent the masonry walls is $11.25 \mathrm{KN} / \mathrm{m}$

- $\quad$ Importance Factor $=1$

- $\quad$ Peak Ground Acceleration, $\mathrm{Z}=0.3$

- $\mathrm{S}_{\mathrm{s}}$, Spectral Response Acceleration at short periods; $\mathrm{S}_{\mathrm{s}}$ $=2.5 \mathrm{Z}$ [Amendment $\mathrm{n}^{\circ} 3$ to SI 413 (2009)]

- $\quad \mathrm{S}_{1}$, Spectral Response Acceleration at a period of 1 second; $\mathrm{S}_{1}=1.25 \mathrm{Z}$ [Amendment $\mathrm{n}^{\circ} 3$ to SI 413 (2009)]

- The effects of cracked sections are included in all elements of the numerical models per ACI Table 6.6.3.1.1 [for Beams: 0.35; for Columns: 0.7; for Slabs: 0.25].

- Soil Profile C; Seismic Design Category D; Risk Category II

- $\quad$ Ordinary Plain Concrete Shear walls $\mathrm{R}=1.5$ [ASCE710 Table 12.2-1]

- Over Strength Factor $\Omega_{0}=2.5$ [ASCE7-10 Table 12.2$1]$

- $\quad$ Deflection Amplification Factor Cd = 1.5 [ASCE7-10 Table 12.2-1] 


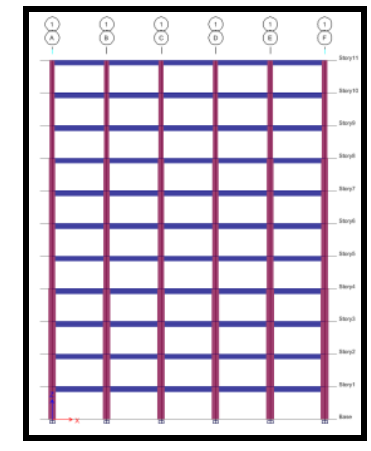

F 1

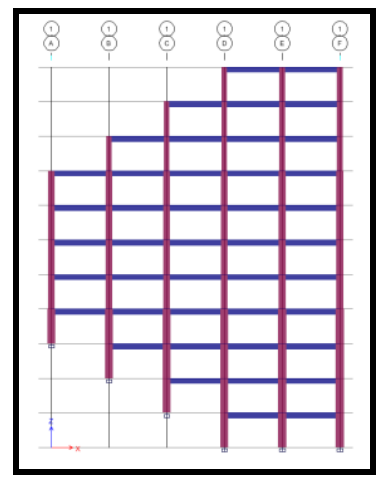

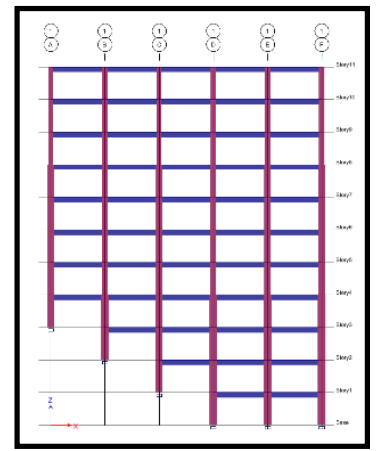

F 2

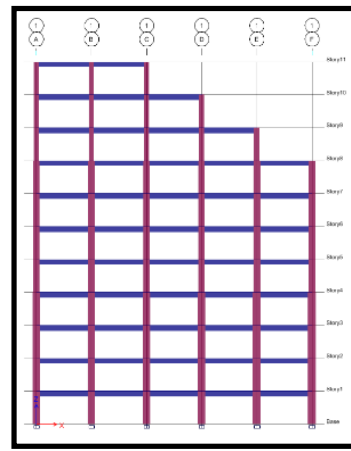

F 3

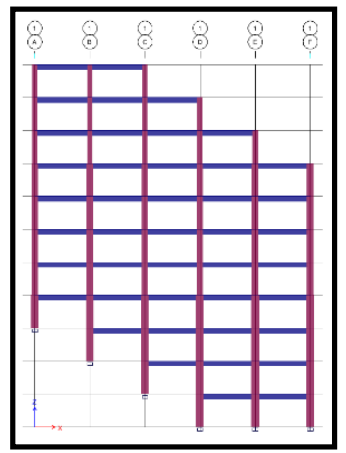

F 4

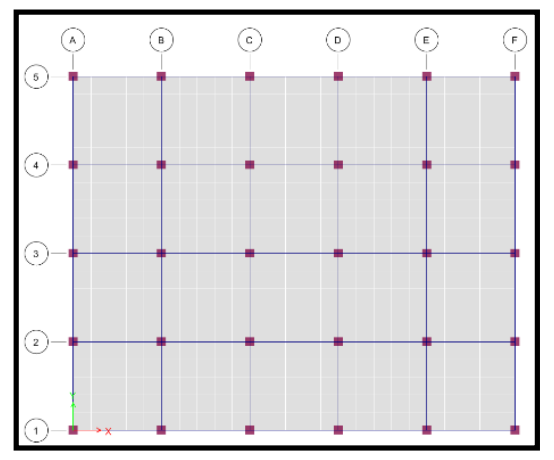

F 5

Figure 1: The Geometry of Model 1, Model 2, Model 3, Model 4 and Model 5 Together with the Typical Floor Plan
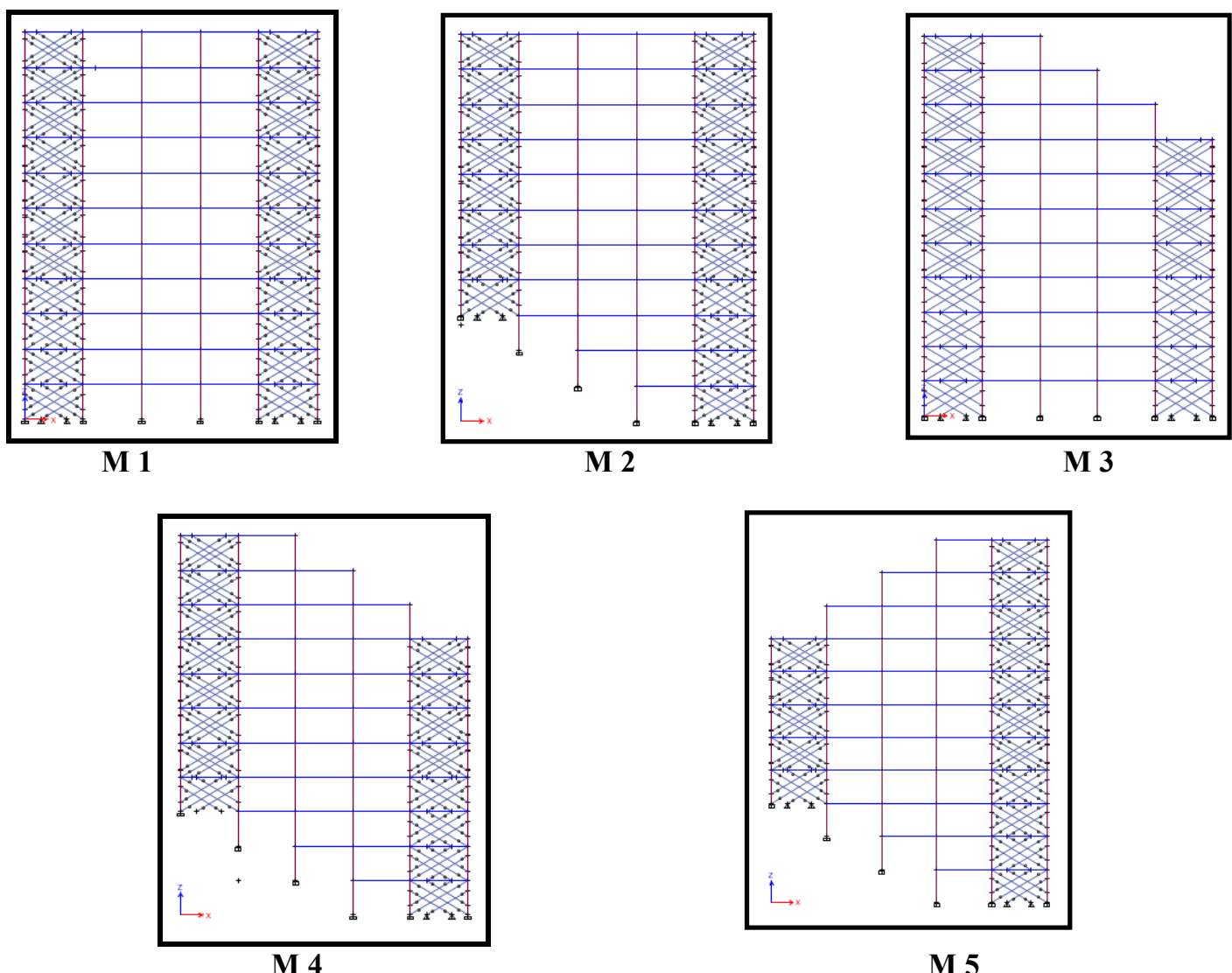

M 5

Figure 2: The Geometry of the Masonry Models 
TABLE 1: BASIC STRUCTURAL AND MATERIAl DATA

\begin{tabular}{|c|c|}
\hline Beam Size & $50 \mathrm{~cm} \times 30 \mathrm{~cm}$ \\
\hline Column Size (first 3 levels) & $70 \mathrm{~cm} \times 70 \mathrm{~cm}$ \\
\hline Column Size (next 4 levels) & $60 \mathrm{~cm} \times 60 \mathrm{~cm}$ \\
\hline Column Size (rest of building) & $50 \mathrm{~cm} \times 50 \mathrm{~cm}$ \\
\hline Wall Thickness & $15 \mathrm{~cm}$ \\
\hline Concrete Grade f c & $28 \mathrm{MPa}$ \\
\hline Grade of Reinforcement Bars & $410 \mathrm{MPa}$ \\
\hline PGA & $0.30 \mathrm{~g}$ \\
\hline$\overline{S_{x}}$ & 0.750 \\
\hline $\mathrm{S}_{1}$ & 0.375 \\
\hline $\begin{array}{c}\text { Modulus of Elasticity } \\
\text { Concrete }\end{array}$ & $30 \times 10^{6} \mathrm{MPa}$ \\
\hline $\begin{array}{c}\text { Modulus of Elasticity } \\
\text { Masonry Material }\end{array}$ & $4.5 \times 10^{6} \mathrm{MPa}$ \\
\hline Poisson Ratio of Concrete & 0.20 \\
\hline Poisson Ratio of Masonry & 0.19 \\
\hline
\end{tabular}

\section{ANALYSIS RESULTS:}

The fundamental parameters of all the structures under investigation are exhibited in Table 2 and in Figure 3. It is evident that Model 1 of all formations enjoys the highest fundamental period. This implies that it is the least robust among the selected structural configurations for resisting seismic forces. Furthermore, the fundamental period of the frame models are comparable to those of the models with infill walls modelled as distributed load. Modeling the infill walls as a distributed load evidently has little bearing, if any, on the magnitude of the structural period. Masonry walls modelled as compression only struts add stiffness thus reduce the period appreciably. Figures 4 and Figure 5 show the maximum displacement in the $\mathrm{x}$ and the $\mathrm{y}$ directions for PGA $=0.30 \mathrm{~g}$.

\begin{tabular}{|c|c|c|c|c|c|c|}
\hline & & 1 & 2 & 3 & 4 & 5 \\
\hline Fundamental & $\mathbf{M}$ & 1.115 & 0.877 & 0.987 & 0.738 & 0.817 \\
\hline \multirow[t]{2}{*}{ Period (sec) } & ML & 3.458 & 2.723 & 3.181 & 2.354 & 2.634 \\
\hline & $\mathbf{F}$ & 3.373 & 2.735 & 3.087 & 2.309 & 2.554 \\
\hline \multirow{3}{*}{$\begin{array}{l}\text { Fundamental } \\
\text { Frequency }(\mathrm{Hz})\end{array}$} & $\mathbf{M}$ & 0.897 & 1.141 & 1.013 & 1.354 & 1.224 \\
\hline & ML & 0.289 & 0.367 & 0.314 & 0.425 & 0.380 \\
\hline & $\mathbf{F}$ & 0.296 & 0.366 & 0.324 & 0.433 & 0.392 \\
\hline \multirow{3}{*}{$\begin{array}{c}\text { Max. } \\
\text { Displacement } \\
(\mathbf{m m})\end{array}$} & $\mathbf{M}$ & $63.0,63.2$ & $52.8,65.5$ & $64.4,72.4$ & $56.5,62.1$ & $54.4,67.2$ \\
\hline & ML & 345.2, 353.7 & $234.7,285.1$ & $335.3,435.5$ & 185.6, 223.9 & 219.1, 312.9 \\
\hline & $\mathbf{F}$ & 328.8, 336.4 & $208.8,296.9$ & $313.9,402.8$ & 177.3, 206 & $224.3,320.8$ \\
\hline
\end{tabular}

Table 2: Fundamental Frequencies, Periods and Maximum Story Displacements 


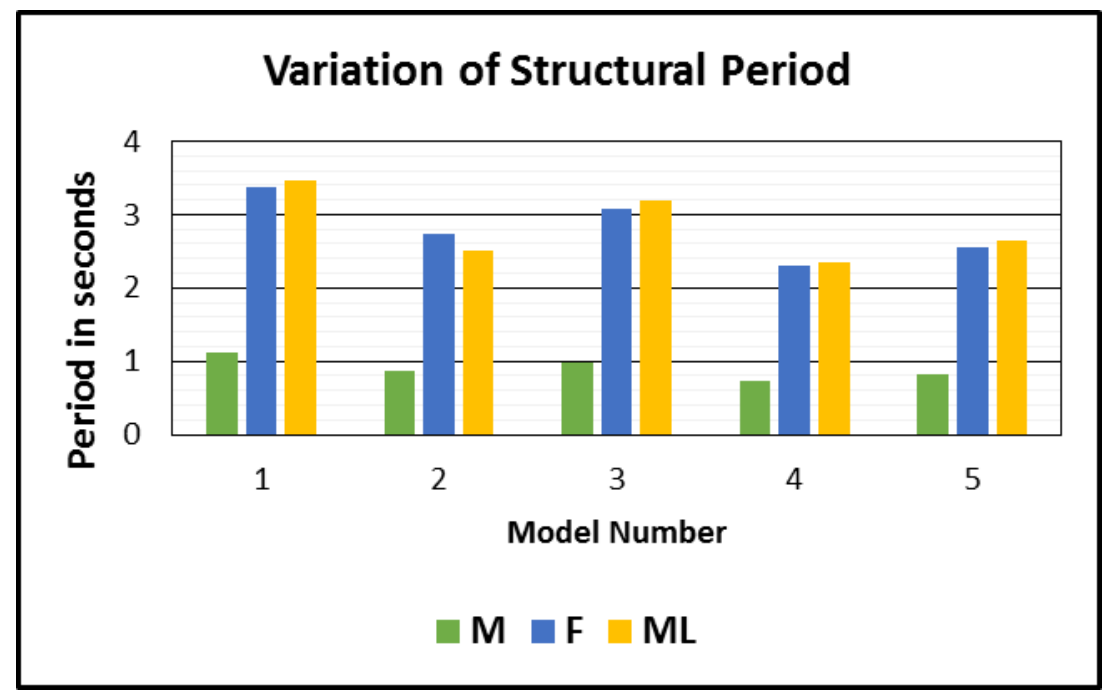

Figure 3: Structural Period for all Models

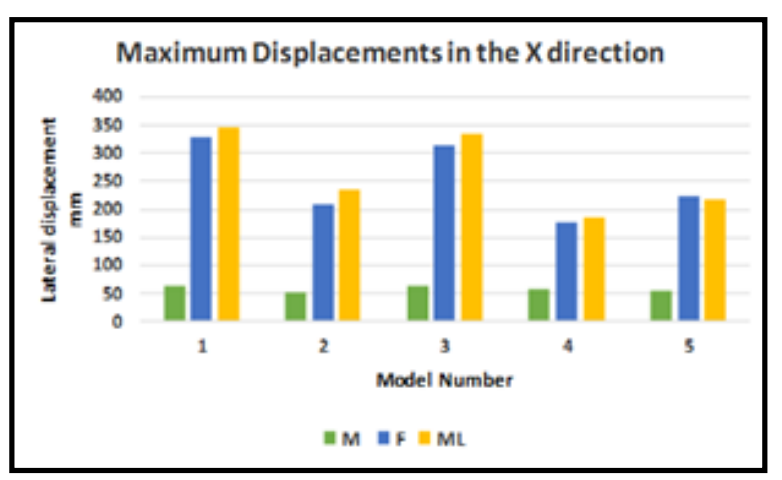

Figure 4: Comparison of Maximum Displacement Values in the Longitudinal Direction

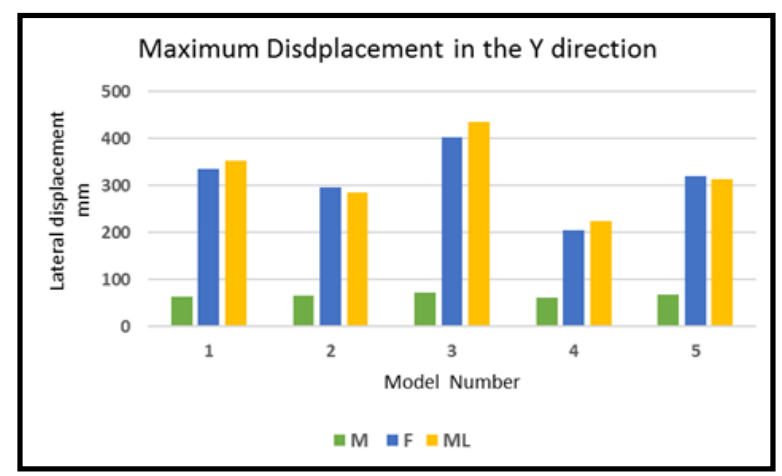

Figure 5: Comparison of Maximum Displacement Values in the Transverse Direction

a) Model M 1 exhibits the maximum lateral deflection in the x-direction of all models, while Model M 4 presents the least lateral displacement. Among the framed models, F 1 endures the maximum deflection while F 5 shows the least deflection. Among the masonry models, ML 1 through ML 5 all show essentially equal deflections in the x-direction.

b) In all models of all configurations, the models in which the walls are represented as continuous loads exhibit the maximum deflection. This is because the mass is appreciably increased while the stiffness remains virtually unchanged leading to a more flexible structure.

c) In the y-direction, Model F3 exhibits the maximum lateral displacements of all models. Among the Masonry models, M3 presents the maximum deflection while M4 shows the least deflection.

d) Granted that all models have drift values below permissible of $60 \mathrm{~mm}$ ASCE 716 [Table 12.12-1] yet it is observed that the drift values change with the storey height in all structural formations. This is manifested in Figure 7. 

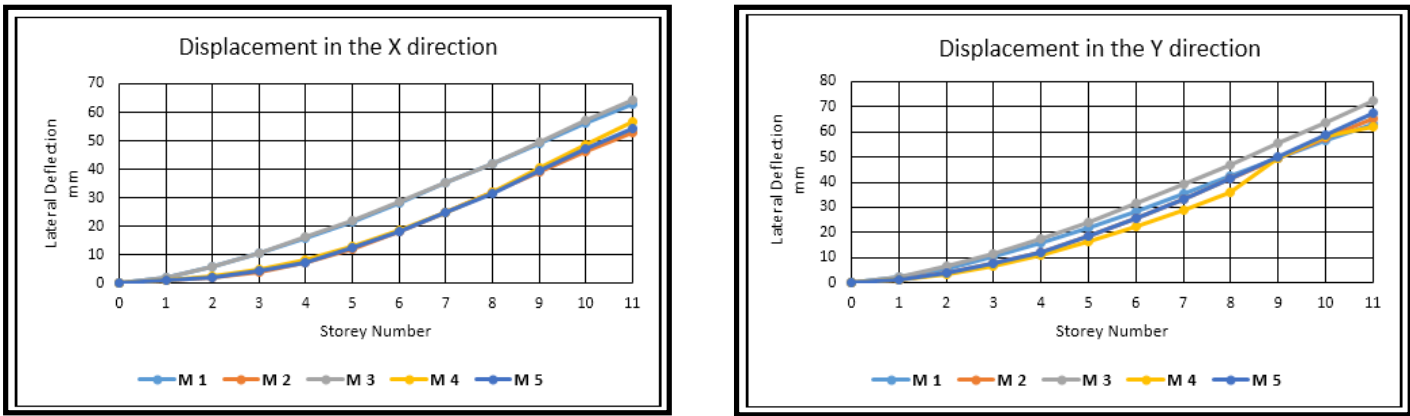

Figure 6: Lateral Displacements in the Longitudinal and Transverse directions
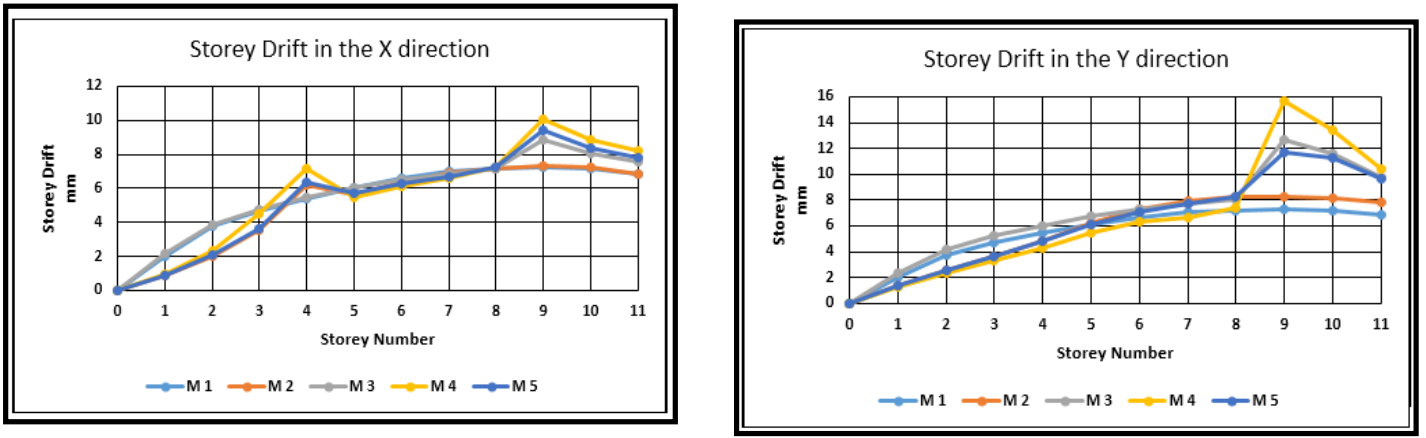

Figure 7: Story Drift in the Longitudinal and Transverse Directions

\section{CONCLUSION:}

Seismic engineering is essentially about controlling lateral deflection. To this end and based on the present narrative it is concluded that masonry walls provide effective means of bracing to otherwise bare frames. They add considerable stiffness if constructed in between periphery columns. Regarding construction of a flat terrain versus on a slope Models M2, M4 and M5 clearly have the edge over models M1 and M3.

\section{REFERENCES}

[1] ASCE 7-12 American Society of Civil Engineers, Minimum Design Load for Buildings and Other Structures.

[2] Building Code Requirements for Structural Concrete, ACI 318-08 and Commentary, American Concrete Institute, Farmington Hills, MI, 2008.

[3] Habibullah, A. et al, (2005) SAP 2000 "Static and Dynamic Finite Element Analysis of Structures", Computers and Structures Inc. Berkeley, California.

[4] Helou S. H. “"An Investigative Seismic study of Structures Built on a Sloping Grade Versus Structures Built With or Without Setbacks, A Colloquial Narration” Second International Conference on Civil Engineering- Palestine, Nov 2019

[5] International Building Code, International Code Council, Washington, D.C. 2009.

[6] Irfanullah M Irshad A Vishwanath B P Seismic Evaluation of Rc Framed Buildings with Influence of masonry infill panel”, International Journal of research and technology eISNN: 2319-1163

[7] Lakshmi G P and Santhi M H, "Seismic Evaluation of Residential Building with Masonry Wall using ETABS”, International Journal of Engineering Sciences \& Research Technology
[8] Magdy Genidy et al "Seismic Response Evaluation of Moment Resisting Frame Multistory Buildings with Soft Story” International Journal of Civil and Structural Engineering Research, vol 3, Issue 1, April 2015

[9] Minimum Design Loads for Buildings and Other Structures, ASCE/SEI 7-10, American Society of Civil Engineers, Reston, VA, 2010.

[10] Rajurkar A. F. and Masram N. K. Seismic Analysis of RC Building with and without Infill Wall”, International Research Journal of Engineering and Technology, Vol. 03, Issue 05, May 2016

[11] S. H. Helou and Ibrahim Muhammad, "Equivalent Lateral Load Method vs. Response Spectrum Analysis; Which Way is Forward"; Asian Journal of Engineering and Technology (ISSN: 2321-2462) Volume 02 - Issue 05, October 2014.

[12] Suresh R. and Narasimhulu K., "Seismic Analysis of Medium Rise Open Ground Storey Framed Building by Response Spectrum Analysis Method”, International Journal for Scientific Research \& Development Vol 5, Issue 10, 2017

[13] Wilson Edward L., 2002. "Three dimensional Static and Dynamic Analysis of Structures", Computers and structures, Inc., Berkeley, California 